\title{
Detection of Para-Chloroaniline Resulting from the Interaction between Sodium Hypochlorite and Chlorhexidine Analyzed by Mass Spectrometry
}

\author{
Miriam Muñoz Arratia1, María de Lourdes Lanzagorta Rebollo', Francisco Javier Pérez Flores², \\ Rodolfo García Contreras ${ }^{3}$, José Luis Molinari Soriano ${ }^{4}$, Ana María Fernández Presas1,3* \\ ${ }^{1}$ Instituto de Estudios Avanzados en Odontología "Yury Kutler", Mexico City, Mexico \\ ${ }^{2}$ Instituto de Química, Universidad Nacional Autónoma de México, Mexico City, Mexico \\ ${ }^{3}$ Departamento de Microbiología y Parasitología, Facultad de Medicina, Universidad Nacional Autónoma de México, \\ Mexico City, Mexico \\ ${ }^{4}$ Departamento de Bioquímica y Biología Estructural, Instituto de Fisiología Celular, Universidad Nacional Autónoma de México, \\ México City, Mexico \\ Email: *presas@unam.mx
}

\begin{abstract}
How to cite this paper: Arratia, M.M., de Lourdes Lanzagorta Rebollo, M., Flores, F.J.P., Contreras, R.G., Soriano, J.L.M. and Fernández Presas, A.M. (2019) Detection of Para-Chloroaniline Resulting from the Interaction between Sodium Hypochlorite and Chlorhexidine Analyzed by Mass Spectrometry. American Journal of Analytical Chemistry, 10, 629-640.
\end{abstract}

https://doi.org/10.4236/ajac.2019.1012044

Received: November 15, 2019

Accepted: December 15, 2019

Published: December 18, 2019

Copyright $\odot 2019$ by author(s) and Scientific Research Publishing Inc. This work is licensed under the Creative Commons Attribution International License (CC BY 4.0).

http://creativecommons.org/licenses/by/4.0/

(c) (i) Open Access

\begin{abstract}
$5.1 \%$ of sodium hypochlorite $(\mathrm{NaOCl})$ mixed with $2 \%$ of chlorhexidine (CHX) forms a brown precipitate that corresponds to para-chloroaniline (PCA), whether PCA is formed after the combination of $\mathrm{NaOCl}, \mathrm{CHX}$, and ethylenediaminetetraacetic acid (EDTA) by means of electron impact (high resolution and interlaced scanning) and ionization by fast atom bombardment (FAB), was analyzed. The brown precipitate, showed signals 127 and $153 \mathrm{Da}$, corresponding to $p$-chloroaniline and $p$-chlorophenyl isocyanate, respectively. These results were analyzed and compared with signals from the interlaced scanning program and confirmed with high resolution mass spectrometry analysis and compared with the NIST database. The mass spectra of this precipitated after different days confirmed the evolution of byproducts with the presence of a peak $m / z=127$, due to the decrease of the fragment $m / z=153$, which disappeared after 180 days. A blue and a white precipitate were observed by the addition of CHX (2\%) with or without polyethylene glycol, respectively, EDTA (17\%) and $\mathrm{NaOCl}$ (5.1\%) precipitates contain chlorhexidine $(m / z=505)$, but no PCA was detected. We confirmed that PCA is not formed directly as a byproduct of CHX oxidation, but through the formation of the para-chlorophenyl isocyanate intermediate, which degrades slowly to PCA.
\end{abstract}




\section{Keywords}

Chlorhexidine, Para-Chloroaniline, Para-Chlorophenyl Isocyanate, EDTA, Sodium Hypochlorite

\section{Introduction}

Bacteria and their products are the major etiologic factors in the initiation, propagation, and persistence of periradicular periodontitis [1] [2]. The host's response to a microbial infection can consist of non-specific inflammation and/or specific immunological reactions. The infection is produced by the invasion of microbes causing tissue damage. Endodontic disease (pulpal and periradicular) is the result of both the pathogenic effects of the microbes and the response of the host. The goal of clinicians is to disrupt and destroy the microbial ecosystem associated with the disease process [3]. The aim of the root canal treatment is to eliminate bacteria from the infected root canal and to prevent reinfection. Biochemical cleaning and shaping of the root canal greatly reduce the number of bacteria [4]. The chemical debridement can take the form of intracanal medicaments, irrigants, or lubricants that facilitate the removal of the organic and inorganic components inside the root canal system. Antimicrobial rinses are used to decrease the microbial loads within the system before obturation and to reduce the potential for failure in the future [5]. Root canal cleaning and disinfection during chemomechanical preparation relies heavily on irrigants because of the anatomic complexities of the pulp canal system. Ideally, irrigants should have antimicrobial and tissue-dissolution actions, as well as other advantageous properties, such as lubrication, demineralization, and the ability to remove debris and the smear layer [6]. Sodium hypochlorite $(\mathrm{NaOCl})$, at a concentration range from $0.5 \%$ to $6 \%$ [7] [8] [9], has been recommended as endodontic irrigant due to its ability to dissolve organic matter together with its broad antimicrobial action [10]. However, $\mathrm{NaOCl}$ has been shown also to have cytotoxic effects that can cause irritation and necrosis of periapical tissues [8] [11]. Furthermore, $\mathrm{NaOCl}$ and EDTA (ethylenediaminetetraacetic acid) have shown to be effective in the elimination of organic and inorganic debris [12] [13] [14].

On the other hand, chlorhexidine gluconate (CHX) is an antimicrobial agent that has been widely used as an effective antiseptic agent applied in endodontic treatment. CHX has also been shown to have antimicrobial substantivity in root dentin for up to 12 weeks [11] [15] [16]. The use of CHX in sequence with $\mathrm{NaOCl}$ can offer antimicrobial substantivity and tissue dissolution, respectively [8] [17]. Successive canal irrigation with $\mathrm{CHX}$ and $\mathrm{NaOCl}$ results in an orange-brown precipitate [18] [19] [20]. The presence of $\mathrm{NaOCl}$ in the canal when CHX is introduced produces a brown-colored precipitate that is very difficult to remove from the canal system [19]. Some of the previously published 
studies claimed that the brown precipitate formed by the interaction between $\mathrm{NaOCl}$ and CHX contains para-chloroaniline (PCA) [18] [20] [21] [22]; however, other studies suggested that this precipitate did not contain PCA [5]. The generation of PCA is a potential consequence of the use of CHX [23]. The International Agency for Research in Cancer (IARC, 2006) classified PCA within the group $2 \mathrm{~B}$, which means that this agent is potentially carcinogenic for humans [24]. The literature reveals controversies regarding the formation of PCA, it is not clear whether PCA is formed after the interaction between $\mathrm{NaOCl}$ and CHX [25].

Therefore, the aim of this study was to analyze the precipitate formed by the mixture of $5.1 \% \mathrm{NaOCl}, 2 \% \mathrm{CHX}$, and $17 \%$ of EDTA by means of electron impact (high resolution and interlaced scanning), and ionization by fast atom bombardment (FAB).

\section{Experimental}

\subsection{Reagents and Materials}

Commercially available samples of $2 \%$ chlorhexidine gluconate in liquid presentation with polyethylene glycol (Consepsis Chlorhexidine Antibacterial Solution, Ultradent Products, Inc., South Jordan, UT, USA), imported by VAMASA, S.A. de C.V. Monterrey, NL, Mexico, 20\% chlorhexidine digluconate solution in $\mathrm{H}_{2} \mathrm{O}$ (Sigma Aldrich, St. Louis, MO, USA), and 9.8\% PCA (4-Chloroaniline, Sigma_Aldrich, St. Louis, MO USA) were used.

\subsection{Procedures}

To prepare $2.0 \% \mathrm{CHX}$, with or without polyethylene glycol, was diluted with $90 \mathrm{~mL}$ distilled water. The chemicals analyzed in this study were: polyethylene glycol 400 (Fluka Chemika 81170), EDTA at 17\%, (Aqueous Irrigant Roth International LTD, Chicago, IL, USA) and $\mathrm{NaOCl}$ (Cloralex, Alen del Norte S.A de C.V., NL, Mexico) at 5.1\%, concentration, which was established by determining active chlorine and was obtained from commercial sources and used without further purification. Analyses were performed at the Department of Analytical Control of the School of Chemistry, UNAM. The experiments were performed at room temperature in the dark during the whole analyzed period.

CHX (2\%) with (Consepsis) or without (Sigma) polyethylene glycol was added slowly to a solution of $3 \mathrm{~mL}$ of $\mathrm{NaOCl}(5.1 \%)$ in an Erlenmeyer flask under constant agitation during $1 \mathrm{~min}$. The suspension obtained was introduced into a 15-mL polypropylene (PP) centrifuge tube. A brown precipitate was recovered from the suspension, which was filtered and washed with acetone to remove traces of polyethylene glycol. Then, the precipitate was collected with a spatula and placed into a flat-top $1.5 \mathrm{~mL}$ polypropylene microtube.

A combination of $\mathrm{NaOCl}(5.1 \%)$, EDTA (17\%), and CHX gluconate (2\%) with (Consepsis) or without polyethylene glycol (Sigma) was analyzed. This solution 
was prepared by the addition of $3 \mathrm{~mL}$ of $\mathrm{NaOCl}$ and $3 \mathrm{~mL}$ of EDTA to an Erlenmeyer flask under constant agitation during $3 \mathrm{~min}$, then $3 \mathrm{~mL}$ of $\mathrm{CHX}$ was added and stirred for $1 \mathrm{~min}$. A blue-colored or a white precipitate was recovered from the above-described mixture, depending on the presence or absence of polyethylene glycol in the suspension. The suspension that contained $\mathrm{NaOCl}$ and CHX with polyethylene glycol was analyzed for $24 \mathrm{~h}$, and for 10, 20, 60, 90, 150, and 180 days (Table 1 ). The analysis of the brown precipitate after 60 days was performed through the interlaced scanning experiment, which consists of choosing the signals of interest $(127,153)$. The results showed signals that corresponded only to the fragments originated by the chosen signal, eliminating all other signals.

Table 1. Summary of the analyses of the different combinations.

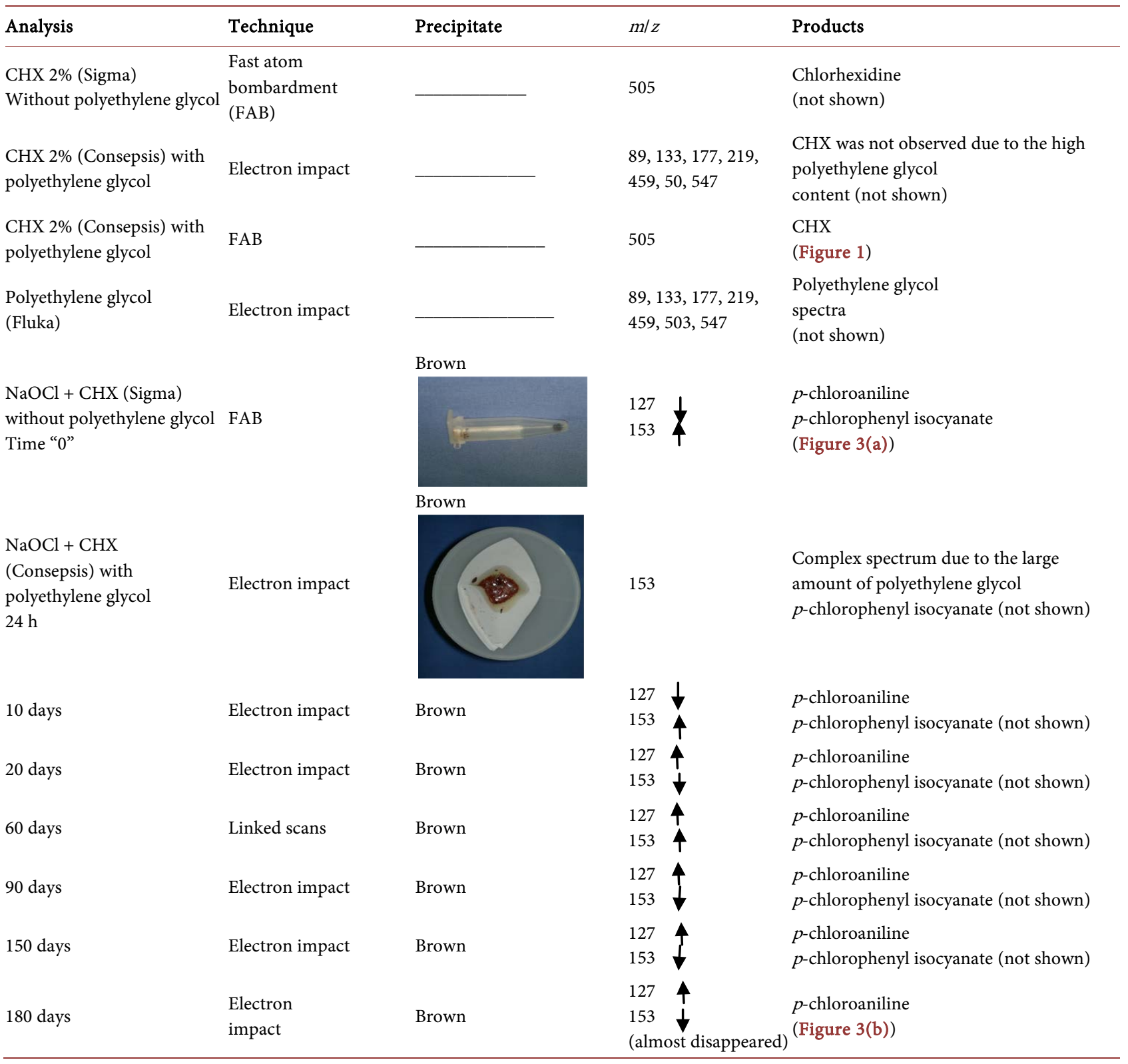




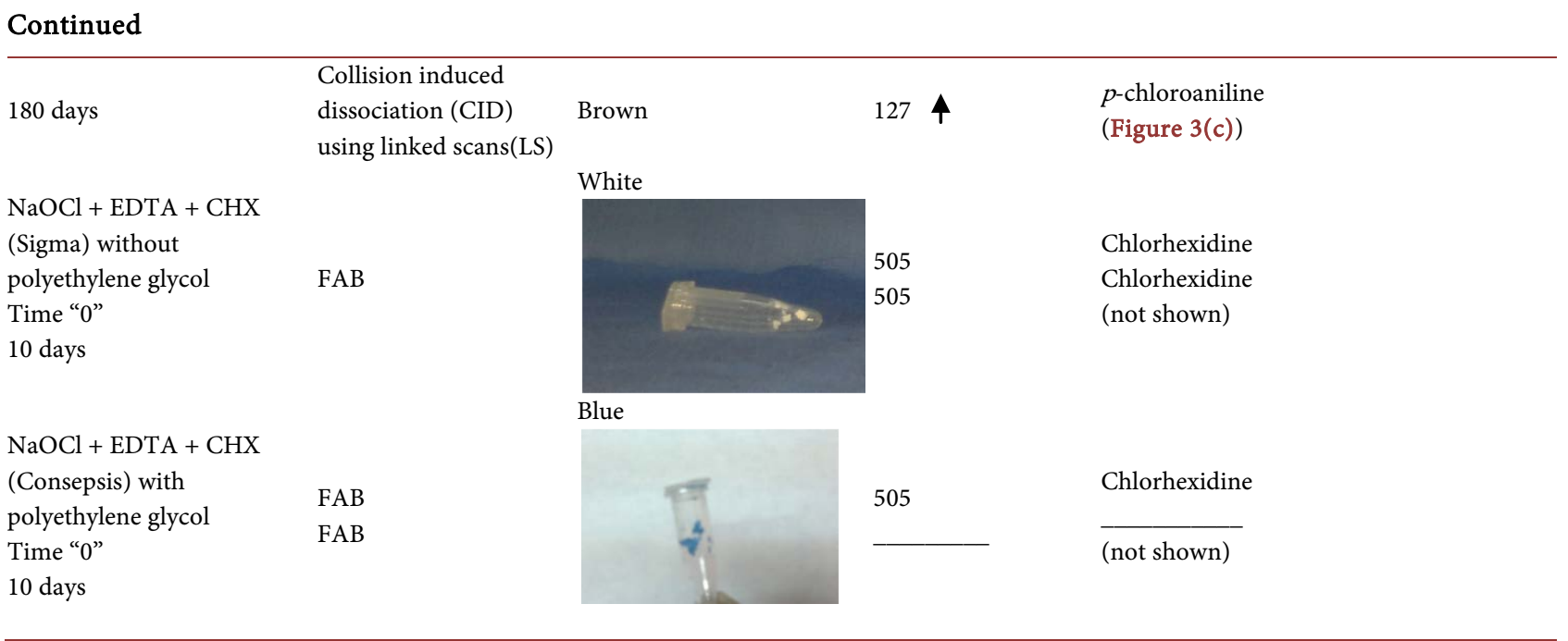

\subsection{Instruments}

Mass spectra were obtained using a JEOL JMS-SX102A instrument with m-nitrobenzyl alcohol as the matrix ( $\mathrm{FAB}^{+}$mode). EIMS and CID-LS measurements were made using a JEOL JMS-700 M Station (Tokyo, Japan) mass spectrometer.

\section{Results}

The structure of chlorhexidine (Consepsis) was confirmed using the positive FAB (fast atom bombardment) ionization mass spectrometry technique. It molecular weight is $m / z=504+1 \mathrm{Da}$ as shown in Figure 1. The mass spectra of PCA (Sigma-Aldrich) showed the mean peak at $\mathrm{m} / \mathrm{z}=127$ (not shown).

The color change and formation of a precipitate were observed after adding $2.0 \%$ of $\mathrm{CHX}$ to $\mathrm{NaOCl}$ (Table 1). The composition of the brown precipitate was studied through $\mathrm{FAB}^{+}$mode and additionally, high resolution mass spectrometry analyses were performed. The results obtained after the $\mathrm{FAB}^{+}$analysis, agree with the reported database for the aforementioned structures (see Figures 2(a)-(d) in supporting information). Mass spectra of the brown precipitate initially showed the mean peak at $\mathrm{m} / z=153$ with $100 \%$ of relative abundance and a secondary peak $\mathrm{m} / z=127$ corresponding to $p$-chlorophenyl isocyanate and $p$-chloroaniline, respectively as shown in Figure 3(a), Table 1.

The mass spectra analysis of the brown solution performed at days 20,60, 90, 150 , and 180 showed the base peak $\mathrm{m} / z=127$ as a result of the consumption of fragment $m / z=153$, which almost disappeared after 180 days Table 1 . This brown precipitate was also analyzed by collision induced dissociation (CID) using linked-scans (LS) at constant $\mathrm{B} / \mathrm{E}$ to detect daughter fragments of $p$-chloroaniline $(m / z=127)$ as shown in Figure $3(\mathrm{~b})$ and Figure $3(\mathrm{c})$, Table 1.

Whereas the addition of $2.0 \%$ of CHX with or without polyethylene glycol plus $17 \% \mathrm{EDTA}$ and $5.1 \% \mathrm{NaOCl}$ induced a blue and a white precipitate, respectively, corresponding to CHX with a peak $\mathrm{m} / z=505$ (Table 1). 


\section{Discussion}

The aim of this study was to analyze by mass spectrometry the products obtained by the degradation of $\mathrm{CHX}$ with $\mathrm{NaOCl}$, as oxidant reagent, and the same reaction using polyethylene glycol and EDTA. Although, there are similar studies in the literature reporting the presence of PCA as the final product of the reaction in the precipitate formed with the mixture of $\mathrm{CHX}$ and $\mathrm{NaOCl}$ [19] [20] [26] [27] [28] [29] [30] in other studies, PCA formation is not detected in the reaction mixture even after long periods of time [5] [25]. Thomas and Sem

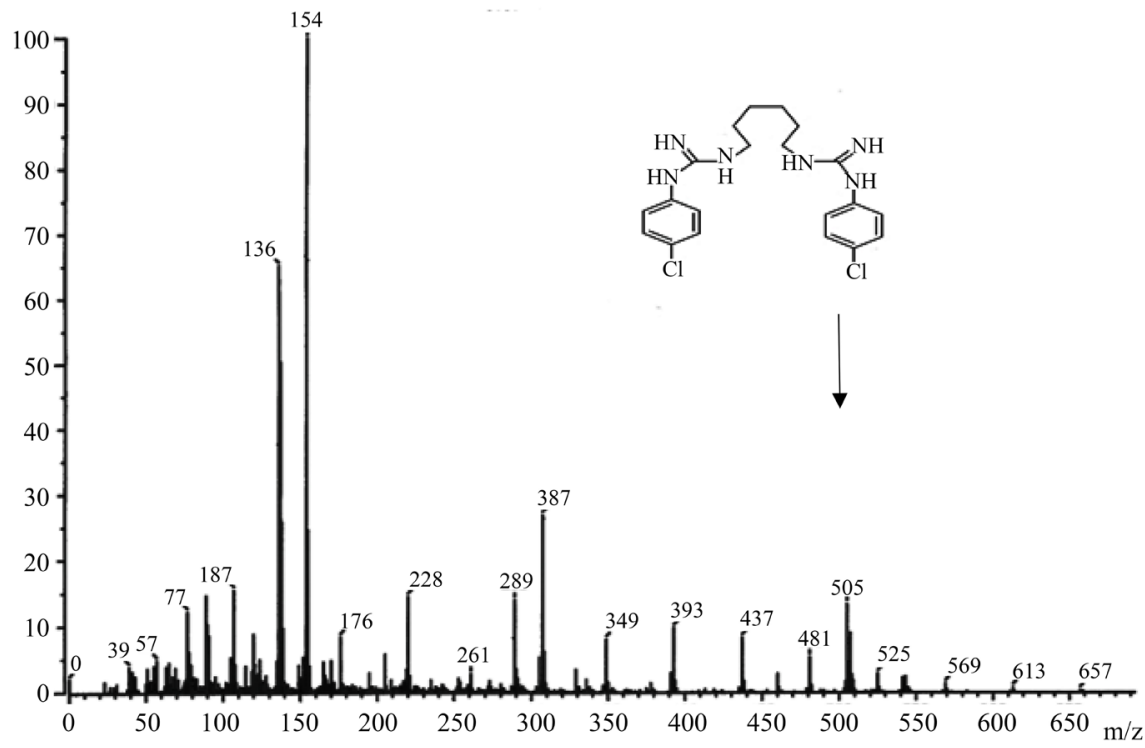

Figure 1. Mass spectra of chlorhexidine $(\mathrm{m} / \mathrm{z}=505)$ with polyethylene glycol (Consepsis) obtained by $\mathrm{FAB}^{+}$.

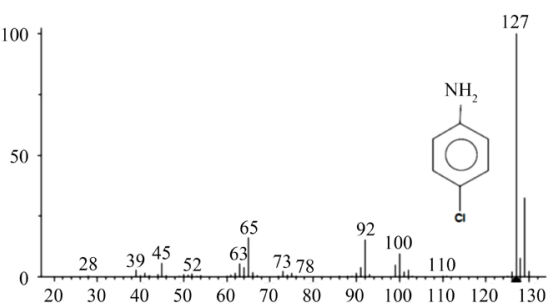

(a)

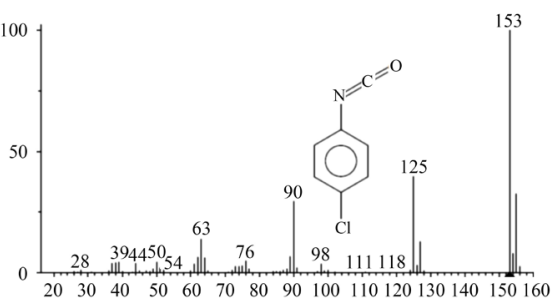

(c)

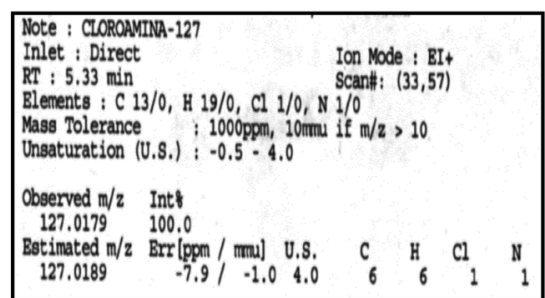

(b)

\begin{tabular}{|c|c|c|c|c|c|c|}
\hline \multicolumn{7}{|c|}{ 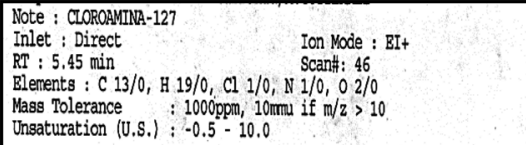 } \\
\hline $\begin{array}{c}\text { Observed } \mathrm{m} / \mathrm{z} \\
152.9981\end{array}$ & $\begin{array}{l}\text { Int8 } \\
24.4\end{array}$ & & & & & \\
\hline $\begin{array}{l}\text { Estimated } \mathrm{m} / \mathrm{z} \\
152.9981\end{array}$ & $\begin{array}{ccc}\operatorname{Err}[\mathrm{ppm} / \mathrm{mmu}] & U . S . \\
-0.3 /+0.0 & 6.0\end{array}$ & c & ${ }_{4}^{H}$ & $\mathrm{Cl}_{1}$ & $\mathbb{N}_{1}$ & $0_{1}^{0}$ \\
\hline
\end{tabular}

(d)

Figure 2. (a) Mass spectra of $p$-chloroaniline of NIST data base; (b) High resolution mass spectrometry analysis data of $p$-chloroaniline $(\mathrm{m} / z=127)$; (c) Mass spectra of p-chlorophenyl isocyanate of NIST database; (d) High resolution mass spectrometry analysis data of $p$-chlorophenyl isocyanate $(\mathrm{m} / \mathrm{z}=153)$. 

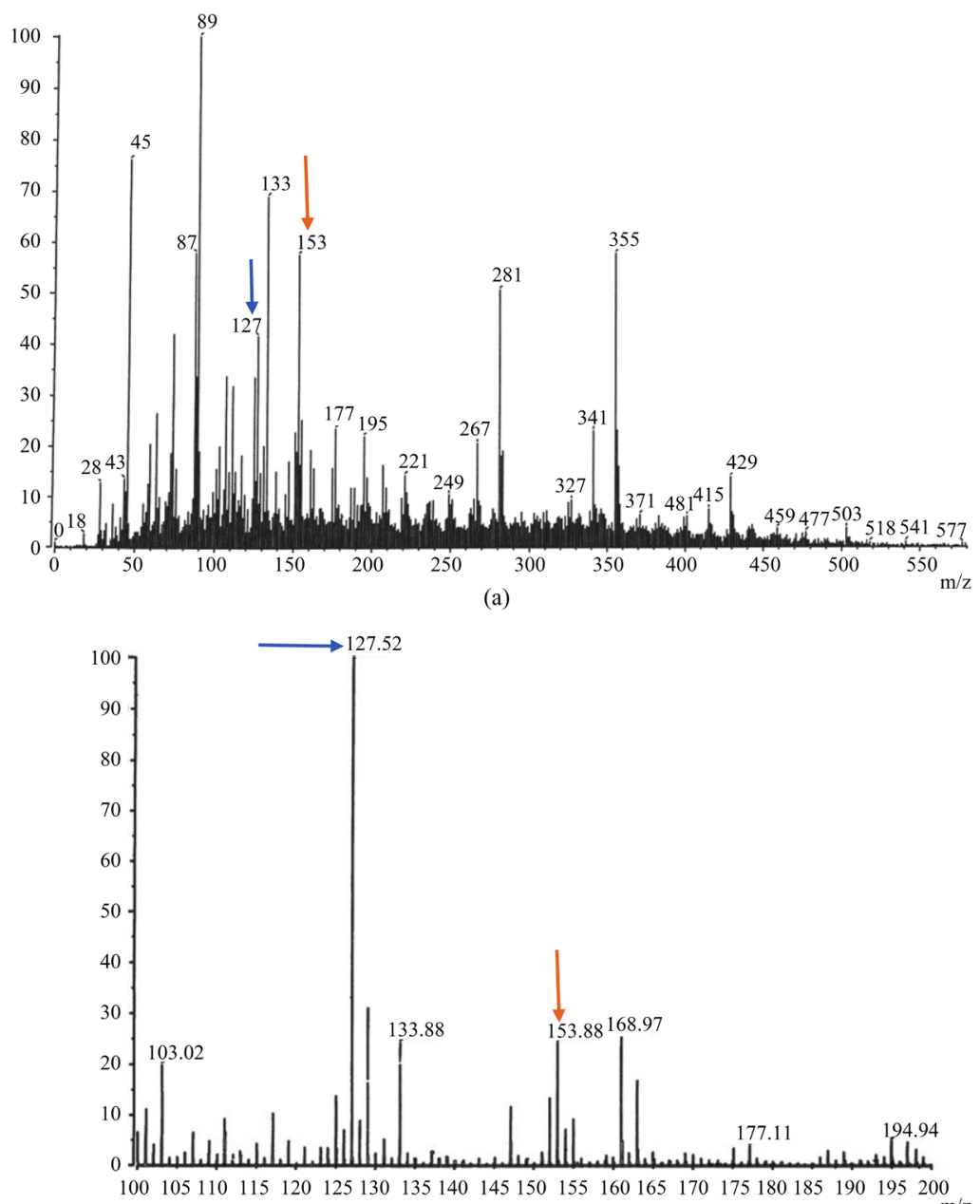

(b)

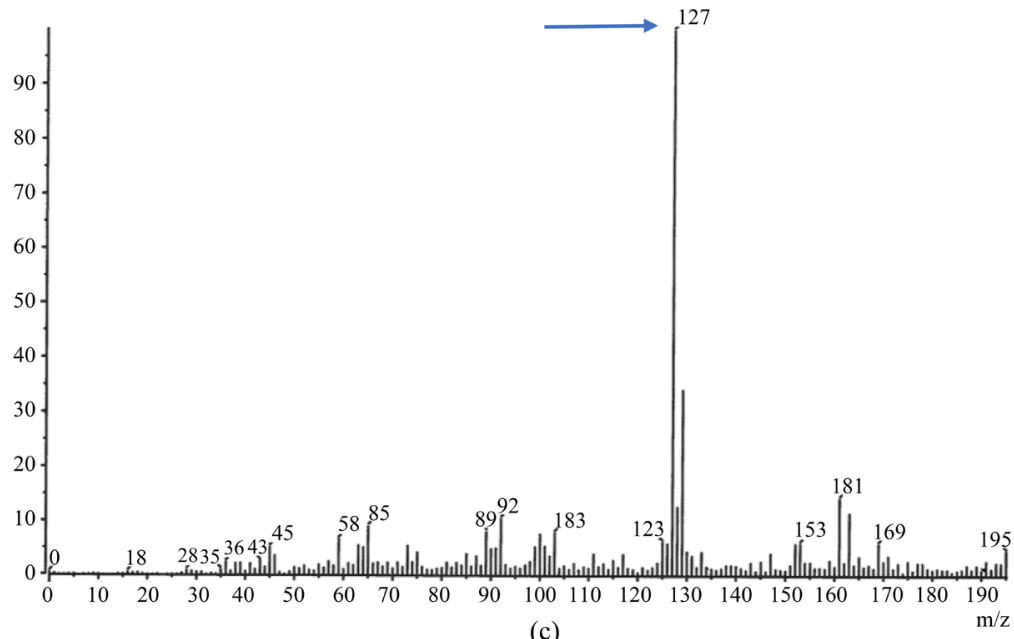

Figure 3. (a) Mass spectra of brown solution corresponding to the oxidation of the chlorhexidine $(\mathrm{CHX})$ solution with sodium hypochlorite solution. $\mathrm{m} / z=127$ and 153 correspond to $p$-chloroaniline $\longrightarrow$ and $p$-chlorophenyl isocyanate. $\longrightarrow$; (b) Electron impact spectrum (EIMS) of the brown precipitate obtained from the combination of $\mathrm{NaOCl}$ with $\mathrm{CHX}$ (Consepsis) for 180 days; (c) Mass spectra of the brown solution after (180 days) analyzed by collision induced dissociation (CID) using linked-scans (LS) at constant $\mathrm{B} / \mathrm{E}$ of $m / z=127$. 
(2010) did not detect PCA in the reaction mixture analyzed by nuclear magnetic resonance (NMR), although they proposed the partial formation of PCA [5]. Nowicki and Sem (2011) analyzed the same mixture [31] and reported the presence of derivatives of benzene ( $p$-chlorophenyl urea and chlorophenyl guanidine), which can be transformed into PCA [32] [33] [34]. On the other hand, the analysis by nuclear magnetic resonance spectroscopy and infrared spectroscopy of the precipitate formed after mixing $\mathrm{NaOCl}$ and QMix 2 did not reveal free PCA [35]. Although, Basrani reported, in 2007, the presence of characteristic peaks obtained from the fragmentation of CHX through mass spectrometry methods $(m / z=127,153,170$, and 195), identification of the fragments and the proposal of a mechanism were not performed [20]. The non-identification of PCA in the reaction mixture by certain techniques evidences that it is necessary to search for appropriate techniques for the analysis of this reaction. Herein, we showed that a useful method for the study of CHX degradation to PCA is mass spectrometry. The fragmentation pattern of the reaction mixture was subjected to FAB ionization mode. All fragments were confirmed by high resolution analysis, using electron impact mass spectrometry (EIMS). Finally, daughter ions of the main peak $(m / z=127)$ corresponded unequivocally to PCA that were detected by collision induced dissociation (CID) using linked-scans (LS) at constant $\mathrm{B} / \mathrm{E}$.

The mass spectrometry data $\left(\mathrm{FAB}^{+}\right.$mode) of the monitored reaction mixture showed characteristic peaks at $m / z=127,153,170$, and 195 . We found that the $\mathrm{m} / z=153$, which corresponds to $p$-chlorophenyl isocyanate, is an initial byproduct of the oxidation reaction. However, the fact that its abundance is inversely proportional to the $127 \mathrm{~m} / z$ peak (PCA) suggests that $p$-chlorophenyl isocyanate $(m / z=153)$ is an intermediate than can react to finally produce PCA $(m / z=$ 127).

Barbin et al. reported that many factors are involved in the degradation time of CHX to PCA [31]. Our study confirmed that the presence of polyethylene glycol in the reaction mixture decreases the reaction rate for the formation of PCA, as shown in Table 1.

On the other hand, our results show that the introduction of EDTA (17\%) in the reaction mixture of $\mathrm{CHX}$ with $\mathrm{NaOCl}$, in the presence or absence polyethylene glycol, inhibits immediately the formation of PCA even after 10 days. The ability of EDTA to inhibit the oxidation reaction can be explained by the presence of active chlorine in $\mathrm{NaOCl}$ that interacts with EDTA forming a stable compound, which does not react with CHX, as reported by Clarkson [36] [37]. Therefore, the use of EDTA as an intermediate irrigating agent applied between $\mathrm{NaOCl}$ and $\mathrm{CHX}$ is an efficient method to inhibit the reaction. We agree with Kolosowski [21] and Rasimick [38], who demonstrated that EDTA does not degrade CHX into PCA, hence, fostering the antimicrobial effect of both solutions.

\section{Conclusion}

Although further studies are necessary to determine the presence of minimal 
concentrations of $\mathrm{CHX}$ in the mixture of the monitored oxidation reaction, we conclude, under the limitations of this study, that $p$-chlorophenyl isocyanate is an intermediate in the oxidation reaction of $\mathrm{CHX}$ into PCA. Furthermore, we demonstrated that polyethylene glycol decreases efficiently the reaction rate for the formation of PCA. Oppositely, the presence of EDTA inhibits completely the oxidation reaction due to its interaction with the active chlorine present in $\mathrm{NaOCl}$ inducing a compound without oxidation properties.

\section{Acknowledgements}

This research was supported by grant \#IN218419 from PAPITT, DGAPA, UNAM, Mexico City, and partially funded by the Departamento de Microbiología y Parasitología, Facultad de Medicina, Universidad Nacional Autónoma de México.

\section{Conflicts of Interest}

The authors deny any conflicts of interest related to this study.

\section{References}

[1] Kakehashi, S., Stanley, H.R. and Fitzgerald, R.J. (1965) The Effects of Surgical Exposures of Dental Pulps in Germ-Free and Conventional Laboratory Rats. Oral Surgery, Oral Medicine, Oral Pathology, Oral Radiology, and Endodontology, 20, 340-349. https://doi.org/10.1016/0030-4220(65)90166-0

[2] Moller, A.J., Fabricius, L., Dahlen, G., Ohlman, A.E. and Heyden, G. (1981) Influence on Periapical Tissues of Indigenous Oral Bacteria and Necrotic Pulp Tissue in Monkeys. Scandinavian Journal of Dental Research, 89, 475-484. https://doi.org/10.1111/j.1600-0722.1981.tb01711.x

[3] Baumgartner, J.C. (2004) Microbiological and Molecular Analysis of Endodontic Infections. Endodontic Topics, 7, 35-51. https://doi.org/10.1111/j.1601-1546.2004.00061.x

[4] Byström, A. and Sundqvist, G. (1981) Bacteriologic Evaluation of the Efficacy of Mechanical Root Canal Instrumentation in Endodontic Therapy. Scandinavian Journal of Dental Research, 89, 321-328. https://doi.org/10.1111/j.1600-0722.1981.tb01689.x

[5] Thomas, J.E. and Sem, D.S. (2010) An in Vitro Spectroscopic Analysis to Determine Whether Para-Chloroaniline Is Produced from Mixing Sodium Hypochlorite and Chlorhexidine. Journal of Endodontics, 36, 315-317.

https://doi.org/10.1016/j.joen.2009.10.028

[6] Gutmann, J.L. and Lovdahl, P. (2010) Problem Solving in Endodontics. Prevention, Identification and Management. 5th Edition, Mosby, London.

[7] Leonardo, M.R., Tanomaru, F.M., Silva, L.A., et al. (1999) In Vivo Antimicrobial Activity of 2\% Chlorhexidine Used as a Root Canal Irrigating Solution. Journal of Endodontics, 25, 167-171. https://doi.org/10.1016/S0099-2399(99)80135-6

[8] Kuruvilla, J.R. and Kamath, M.P. (1998) Antimicrobial Activity of 2.5\% Sodium Hypochlorite and 0.2\% Chlorhexidine Gluconate Separately and Combined, as Endodontic Irrigants. Journal of Endodontics, 24, 472-476.

https://doi.org/10.1016/S0099-2399(98)80049-6 
[9] Jeansonne, M.J. and White, R.R. (1994) A Comparison of 2.0\% Chlorhexidine Gluconate and 5.25\% Sodium Hypochlorite as Antimicrobial Endodontic Irrigants. Journal of Endodontics, 20, 276-278. https://doi.org/10.1016/S0099-2399(06)80815-0

[10] Zehnder, M. (2006) Root Canal Irrigants. Journal of Endodontics, 32, 389-398. https://doi.org/10.1016/j.joen.2005.09.014

[11] Komorowski, R., Grad, H., Wu, X.Y. and Friedman, S. (2000) Antimicrobial Substantivity of Chlorhexidine-Treated Bovine Root Dentin. Journal of Endodontics, 26, 315-317. https://doi.org/10.1097/00004770-200006000-00001

[12] Goldman, M., Goldman, L.B., Cavaleri, R., Bogis, J. and Lin, P.S. (1982) The Efficacy of Several Irrigating Solutions for Endodontics: A Scanning Electron Microscopic Study, Part 2. Journal of Endodontics, 8, 487-492. https://doi.org/10.1016/S0099-2399(82)80073-3

[13] Yamada, R.S., Armas, A., Goldman, M. and Lin, P.S. (1983) A Scanning Electron Microscopic Comparison of a High Volume Final Flush with Several Irrigating Solutions: Part 3. Journal of Endodontics, 9, 137-142. https://doi.org/10.1016/S0099-2399(83)80032-6

[14] Baumgartner, J.C. and Mader, C.L. (1987) A Scanning Electron Microscopic Evaluation of Four Root Canal Irrigation Regimens. Journal of Endodontics, 13, 147-157. https://doi.org/10.1016/S0099-2399(87)80132-2

[15] Rosenthal, S., Spångberg, L. and Safavi, K. (2004) Chlorhexidine Substantivity in Root Canal Dentin. Oral Surgery, Oral Medicine, Oral Pathology, Oral Radiology, and Endodontology, 98, 488-492. https://doi.org/10.1016/j.tripleo.2003.07.005

[16] White, R.R., Hays, G.L. and Janer, L.R. (1997) Residual Antimicrobial Activity after Canal Irrigation with Chlorhexidine. Journal of Endodontics, 23, 229-217. https://doi.org/10.1016/S0099-2399(97)80052-0

[17] Kishen, A., Sum, C.P., Mathew, S. and Lim, C.T. (2008) Influence of Irrigation Regimens on the Adherence of Enterococcus faecalis to Root Canal Dentin. Journal of Endodontics, 34, 850-854. https://doi.org/10.1016/j.joen.2008.04.006

[18] Basrani, B.R., Manek, S., Sodhi, R.N. and Fillery, E. (2007) Interaction between Sodium Hypochlorite and Chlorhexidine Gluconate. Journal of Endodontics, 33, 966-969. https://doi.org/10.1016/j.joen.2007.04.001

[19] Bui, T.B., Baumgartner, J.C. and Mitchell, J.C. (2008) Evaluation of the Interaction between Sodium Hypochlorite and Chlorhexidine Gluconate and Its Effect on Root Dentin. Journal of Endodontics, 34, 181-185. https://doi.org/10.1016/j.joen.2007.11.006

[20] Basrani, B.R., Manek, S. and Mathers, D. (2010) Determination of 4-Chloroaniline and Its Derivatives Formed in the Interaction of Sodium Hypochlorite and Chlorhexidine by Using Gas Chromatography. Journal of Endodontics, 36, 312-314. https://doi.org/10.1016/j.joen.2009.10.031

[21] Kolosowski, K.P., Sodhi, R.N., Kishen, A. and Basrani, B.R. (2014) Qualitative Analysis of Precipitate Formation on the Surface and in the Tubules of Dentin Irrigated with Sodium Hypochlorite and a Final Rinse of Chlorhexidine or QMiX. Journal of Endodontics, 40, 2036-2040. https://doi.org/10.1016/j.joen.2014.08.017

[22] Mortenson, D., Sadilek, M., Flake, N.M., et al. (2012) The Effect of Using an Alternative Irrigant between Sodium Hypochlorite and Chlorhexidine to Prevent the Formation of Para-Chloroaniline within the Root Canal System. International Endodontic Journal, 45, 878-882. https://doi.org/10.1111/j.1365-2591.2012.02048.x

[23] Havlíková, L., Matysová, L., Nováková, L., Hájková, R. and Solich, P. (2007) HPLC 
Determination of Chlorhexidine Gluconate and p-Chloroaniline in Topical Ointment. Journal of Pharmaceutical and Biomedical Analysis, 43, 1169-1173. https://doi.org/10.1016/j.jpba.2006.09.037

[24] World Health Organization. International Agency for Research on Cancer (IARC) (1993) Occupational Exposures of Hairdressers and Barbers and Personal Use of Hair Colourants; Some Hair Dyes, Cosmetic Colourants, Industrial Dyestuffs and Aromatic Amines. Monography on the Evaluation of Carcinogenic Risks to Human Volume 57, Lyon, 305-321.

[25] Orban, E.O., Irmak, Ô., Yaman, B.C. and Karabucak, B. (2016) Does Para-Chloroaniline Really Form after Mixing Sodium Hypochlorite and Chlorhexidine? Journal of Endodontics, 42, 455-459. https://doi.org/10.1016/j.joen.2015.12.024

[26] Krishnamurthy, S. and Sudhakaran, S. (2010) Evaluation and Prevention of the Precipitate Formed on Interaction between Sodium Hypochlorite and Chlorhexidine. Journal of Endodontics, 36, 1154-1157. https://doi.org/10.1016/j.joen.2010.01.012

[27] Chhabra, R.S., Huff, J.E., Haseman, J.K., et al. (1991) Carcinogenicity of p-Chloroaniline in Rats and Mice. Food and Chemical Toxicology, 29, 119-124. https://doi.org/10.1016/0278-6915(91)90166-5

[28] Valera, M.C., Chung, A., Menezes, M.M., et al. (2010) Scanning Electron Microscope Evaluation of Chlorhexidine Gel and Liquid Associated with Sodium Hypochlorite Cleaning on the Root Canal Walls. Oral Surgery, Oral Medicine, Oral Pathology, 110, e82-e87. https://doi.org/10.1016/j.tripleo.2010.04.051

[29] Vivacqua-Gomes, N., Ferraz, C.C.R., Gomes, B.P.F.A., et al. (2002) Influence of Irrigants on the Coronal Microleakage of Laterally Condensed Gutta-Percha Root Filling. International Endodontic Journal, 35, 791-795. https://doi.org/10.1046/j.1365-2591.2002.00569.x

[30] Giampiero Rossi, F., Doğramaci, E.J., Guastalli, A.R., Steier, L. and de Figueiredo, J.A. (2012) Antagonistic Interactions between Sodium Hypochlorite, Chlorhexidine, EDTA, and Citric Acid. Journal of Endodontics, 38, 426-431. https://doi.org/10.1016/j.joen.2012.01.006

[31] Barbin, L.E., Estrela, C., Costa Guedes, D.F., Emboava Spanó, J.C., Sousa-Neto, M.D. and Djalma Pécora, J. (2013) Detection of Para-Chloroaniline, Reactive Oxygen Species, and 1-Chloro-4-Nitrobenzene in High Concentrations of Chlorhexidine and in a Mixture of Chlorhexidine and Calcium Hydroxide. Journal of Endodontics, 39, 664-668. https://doi.org/10.1016/j.joen.2012.10.018

[32] Nowicki, J. and Sem, D. (2011) An in Vitro Spectroscopic Analysis to Determine the Chemical Composition of the Precipitate Formed by Mixing Sodium Hypochlorite and Chlorhexidine. Journal of Endodontics, 37, 983-988. https://doi.org/10.1016/j.joen.2011.03.033

[33] Aizawa, H. (1982) Metabolic Maps of Pesticides. Academic Press, New York, 128. https://doi.org/10.1016/B978-0-12-046480-7.50007-3

[34] Nimmo, W.B., Willems, A.G.M., Joustra, K.D. and Verloop, A. (1986) The Degradation of Diflubenzuron and Its Chief Metabolites in Soil. Part II: Fate of Chlorophenylurea. Pesticide Science, 17, 403-411. https://doi.org/10.1002/ps.2780170411

[35] Ozgür, I., Ekim, O.O., Kamarun, G. and Batu, C.Y. (2018) Nuclear Magnetic Resonance Spectroscopy and Infrared Spectroscopy Analysis of Precipitate Formed after Mixing Sodium Hypochlorite and QMix 2in1. PLoS ONE, 13, e0202081. https://doi.org/10.1371/journal.pone.0202081

[36] Clarkson, R.M., Podlich, H.M. and Moule, A.J. (2011) Influence of Ethylenediami- 
netetraacetic Acid on the Active Chlorine Content of Sodium Hypochlorite Solutions When Mixed in Various Proportions. Journal of Endodontics, 37, 538-543. https://doi.org/10.1016/j.joen.2011.01.018

[37] Grande, N.M., Plotino, G., Falanga, A., Pomponi, M. and Somma, F. (2006) Interaction between EDTA and Sodium Hypochlorite: A Nuclear Magnetic Resonance Analysis. Journal of Endodontics, 32, 460-464.

https://doi.org/10.1016/j.joen.2005.08.007

[38] Rasimick, B.J., Nekich, M., Hladek, M.M., Musikant, B.L. and Deutsch, A.S. (2008) Interaction between Chlorhexidine Digluconate and EDTA. Journal of Endodontics, 34, 1521-1523. https://doi.org/10.1016/j.joen.2008.08.039 